\title{
Follow up of activity in rheumatoid arthritis by gray scale US and power Doppler US for 12 months
}

\author{
Rabab H. Ali, Nihal A. Fathi, Esam M. Abu-Alfadl and Hanan S. Mohamed \\ Department of Rheumatology and Rehabilitation, Sohag Faculty of Medicine, Sohag \\ University
}

\begin{abstract}
Introduction: Rheumatoid arthritis (RA) is a chronic inflammatory disease characterized by the development of synovitis, which damages cartilage, bone, ligaments, and tendons. US is available, noninvasive, and relatively inexpensive bedside imaging method with high patient acceptability. This technique is more sensitive and reproducible than clinical evaluation in assessing joint inflammation. Power Doppler (PD) US detect flow from small vessels and low velocity flow at the microvascular level. PD US detects indirect signs of increased vascularization associated with soft tissue musculoskeletal inflammatory and infectious diseases and enteritis in spondyloarthropathies.

Aim of the work: Follow up of RA patients for assessment activity by gray scale and PD during 12 months.

Patients and Methods: longitudinal observational study included 30 Adult patients fulfilling 2010 Rheumatoid arthritis classification criteria: An American College of Rheumatology/European League Against Rheumatism criteria will be included in this study.

Results: There was high significant difference between different times of follow up (start, 6, 12 months) as regards count of swollen joints, tender joints, VAS, and DAS ( $p$ value $<0.001$ ) as mean value of them decreased significantly from start up to 12 months. There was high significant difference between different times of follow up (start, 6, 12 months) as regards RT US gray scale count, LT US gray scale count, Total US gray scale count, and Total US gray scale number ( $p$ value $<0.001$ ) as mean value of them decreased significantly from start up to 12 months

Conclusion: The combination of grey scale US and PD could be used as a sensitive and reliable non-invasive and widely available method complementary to standard clinical assessment for evaluating rheumatoid synovial inflammation in daily management and clinical trials.
\end{abstract}

Keywords: RA, clinical evaluation, musculoskeletal ultrasound

\section{Introduction}

Rheumatoid arthritis (RA) is a
chronic inflammatory disease characterized by the development of synovitis, which damages cartilage, bone, ligaments, and tendons. Assessment of inflammatory activity is essential in daily practice to enable therapeutic decisions and to evaluate disease outcome and response to treatment ${ }^{(\mathbf{1})}$.

In RA, structural damage is associated with pain and functional impairments (1). The presence of synovitis (mainly the number of swollen joints at physical examination) has been recognized as one of the most important predisposing factor of subsequent structural damage (1). Synovial inflammation consists of periarticular vasodilatation followed by synovial proliferation, which is accompanied by angiogenesis resulting in intraarticular Blood vessel formation. Hyper vascularization and angiogenesis of the synovial membrane are considered to be primary 
pathogenic mechanisms responsible for the invasive behavior of rheumatoid pannus (2). Therefore, there is a relationship between joint inflammatory activity and synovial vascularization. Traditionally, the degree of disease activity has been evaluated by measuring subjective clinical variables, laboratory measures, and radiographic findings. However, clinical evaluation of joint pain and swelling have not been sufficiently reliable .In addition, conventional plain radiography depicts indirect signs of cartilage loss and bony erosions due to previous destructive synovial inflammatory activity ${ }^{(3)}$.

US is available, noninvasive, and relatively inexpensive bedside imaging method with high patient acceptability. This technique is more sensitive and reproducible than clinical evaluation in assessing joint inflammation ${ }^{(3)}$.

The greater resolution of superficial musculoskeletal structures offered by high-frequency transducers has promoted an increasing use of US in rheumatic diseases. Several studies have demonstrated that high frequency US is accurate for detecting joint effusion and synovitis. Compared with magnetic resonance imaging (MRI) and direct arthroscopic visualization. In addition, all peripheral joints can be examined as many times as required at the time of consultation, which improves the accuracy of clinical evaluation. while, prosthetic joints do not interfere with US images ${ }^{(4)}$.

Power Doppler (PD) US detect flow from small vessels and low velocity flow at the microvascular level. PD US detects indirect signs of increased vascularization associated with soft tissue musculoskeletal inflammatory and infectious diseases and enteritis in spondyloarthropathies (5).

\section{Aim of the work:}

Follow up of RA patients for assessment activity by gray scale and PD during 12 months.

\section{Patients and Methods:}

Design: longitudinal observational study.

Patients:

This study included 30 Adult patients fulfilling 2010 Rheumatoid arthritis classification criteria: An American College of Rheumatology/European League Against Rheumatism criteria will be included in this study.

\section{Methods:}

\section{Patient assessment:}

- Patients will be under clinical, laboratory, and US evaluation at baseline, 6months and 12 months

- Clinical evaluation will be performed for all patients) and

- The following data will recorded for each patient at study entry: age, sex, symptom duration, morning stiffness, nonsteroidal antiinflammatory drugs (NSAIDs) and corticosteroids received for RA before study entry, DMARDs prescribed, extra articular involvement of RA, and rheumatoid factor, Drugs received for RA, and joint surgery for RA will be recorded at each visit. At each visit, 28 joints including bilateral glenohumeral, elbow, wrist, metacarpophalangeal(MCP), proximal interphalangeal (PIP) of the hands, and knee joints will be assessed for tenderness and swelling. Tender joint count and swollen joint count will be recorded for each patient. A global pain intensity visual analog scale score (VAS pain; range $0-100 \mathrm{~mm}$ ), a VAS score for the patient's overall assessment of disease activity (range 0-100 mm).

\section{Laboratory assessment:}

C-reactive protein (CRP) level, and erythrocyte sedimentation rate (ESR), 
complete blood count (CBC) will be obtained from each patient's.

Disease activity assessment:

Disease activity will be assessed by calculating the 28-joint Disease Activity Score (DAS28).

\section{US assessment:}

A systematic gray-scale PDUS examination of the hand joints.GS synovitis scoring will be evaluated using a 4-grade scale from 0 to 3 with the following subjective definitions for each category

- grade $0=$ absence of synovial thickening;

- grade 1 = mild synovial thickening;

- grade 2 = moderate synovial thickening;

- grade $3=$ marked synovial thickening.

PD synovitis scoring will be evaluated also using a 4-grade scale from 0 to 3 with the following definition for each category:

- grade $0=$ absence of signal, no intraarticular flow;

- grade $1=$ mild, one or two vessels signal (including one confluent vessel) for small joints and two to three signals for large joints (including two confluent vessels);

- grade $2=$ moderate confluent vessels (>grade 1) and less than $50 \%$ of normal area.
- grade 3 = marked vessels' signals in more than half the synovial area.

Joint synovitis will be defined as the presence of intraarticular effusion and/or synovial hypertrophy.

Synovial blood flow will be evaluated by power Doppler in the hand joints. Power Doppler imaging will be performed by selecting a region of interest that included the bony margins, articular space, and a variable view of surrounding tissues

\section{Inclusion criteria:}

1) Patient should to give Informed consent.

2) Patient age at disease onset is more than 16 years old.

3) Patients with rheumatoid arthritis enrolled in this study will be identified clinically and laboratory fulfilling the 2010 Rheumatoid arthritis classification criteria.

\section{Exclusion criteria:}

1) Other forms of connective tissue diseases(systemic lupus erythematosus, sero negative arthropathies.....etc)

2) Hand osteoarthritis.

3) Patients who had traumatic, septic, or microcrystalline arthritis, previous joint surgery, or isotopic synovectomy within the past 12 months before the study will be excluded.

\section{Results}

Mean value of age of our study group was 43 years, with SD 10.5, and ranged from 24 to 60 years, the study group included 28 females (93.3\%) and only 2 males (6.7\%). The mean value of duration of symptoms was 7 years, with SD 4.3, and ranged from 2 to 20 years. 26 patients $(87.6 \%)$ complained of morning stiffness at start of follow up but number of patients who complaining decreased to 13 pts (43.3\%) after 6 months, they became only 9 pts (30\%) after 12 months, and this difference was significant (p value $=0.04$ ) and this was explained by the good control of patient by combination therapy and by adding corticosteroids. Only 2 patients in our study group had extraarticular manifestations at start of follow up and still after 6 months with significant difference ( $\mathrm{p}$ value $=0.002$ ).

There was significant difference regarding RF as $80 \%$ of patients had positive RF at start and this percentage increased significantly to $86.6 \%$ after 6 months, $96.7 \%$ after 12 months. 
There was significant difference between different times of follow up regarding APR as mean of both ESR and CRP decreased significantly from start up to 12 months, on the other hand there was non significant difference regard CBC parematers (WBCs, PLTs, and HB) (Table 1)

There was high significant difference between different times of follow up (start, 6, 12 months) as regards count of swollen joints, tender joints, VAS, and DAS (p value $<0.001)$ as mean value of them decreased significantly from start up to 12 months (Table 2).

There was high significant difference between different times of follow up (start, 6, 12 months) as regards RT US gray scale count, LT US gray scale count, Total US gray scale count, and Total US gray scale number ( $\mathrm{p}$ value $<0.001$ ) as mean value of them decreased significantly from start up to 12 months.

Also there was high significant difference between different times of follow up (start, 6, 12 months) as regards RT US PD score joint count, LT US PD score joint count, Total US PD score count, and Total US PD joint number ( $p$ value $<0.001$ ) as mean value of them decreased significantly from start up to 12 months.

Table 1. Comparison between Laboratory investigations at different times of follow up (Start, after 6 months, and after 12 months)

\begin{tabular}{|c|c|c|c|c|c|c|}
\hline Variable & & At start & $\begin{array}{l}\text { After } 6 \\
\text { months }\end{array}$ & $\begin{array}{l}\text { After12 } \\
\text { months }\end{array}$ & $\begin{array}{c}\text { Chi } \\
\text { square } * / \\
\text { t test } * *\end{array}$ & $\begin{array}{c}P \\
\text { value }\end{array}$ \\
\hline \multicolumn{7}{|l|}{$\mathrm{CBC}$} \\
\hline WBCs & $\begin{array}{c}\text { Mean } \pm \text { SD } \\
\text { Range }\end{array}$ & $\begin{array}{c}8.35 \pm 2.97 \\
4.90-15\end{array}$ & $\begin{array}{c}8.44 \pm 2.57 \\
5.4-14.8\end{array}$ & $\begin{array}{c}8.01 \pm 1.91 \\
5.29-13.10\end{array}$ & $0.223 * *$ & $\begin{array}{c}0.825 \\
\text { (NS) }\end{array}$ \\
\hline HB & $\begin{array}{c}\text { Mean } \pm \text { SD } \\
\text { Range }\end{array}$ & $\begin{array}{c}11.78 \pm 1.34 \\
9-14\end{array}$ & $\begin{array}{c}11.66 \pm 0.965 \\
9.5-13.4\end{array}$ & $\begin{array}{c}11.96 \pm 1.08 \\
9.8-13.6\end{array}$ & $0.749 * *$ & $\begin{array}{l}0.460 \\
(\mathrm{NS})\end{array}$ \\
\hline PLTS & $\begin{array}{c}\text { Mean } \pm \text { SD } \\
\text { Range }\end{array}$ & $\begin{array}{c}318.93 \pm 84.06 \\
90-486\end{array}$ & $\begin{array}{c}342.80 \pm 67.33 \\
196-536\end{array}$ & $\begin{array}{c}339.5 \pm 67.15 \\
187-486\end{array}$ & $1.372 * *$ & $\begin{array}{l}0.180 \\
(\mathrm{NS})\end{array}$ \\
\hline ESR & $\begin{array}{c}\text { Mean } \pm \text { SD } \\
\text { Range }\end{array}$ & $\begin{array}{c}49.87 \pm 25.67 \\
12-102\end{array}$ & $\begin{array}{c}38.5 \pm 27.15 \\
8-102\end{array}$ & $\begin{array}{c}40 \pm 22.8 \\
9-90\end{array}$ & $3.107 * *$ & $\begin{array}{c}0.004 \\
(\mathrm{~S})\end{array}$ \\
\hline \multirow[t]{2}{*}{ CRP } & Mean \pm SD & $16.34 \pm 12.58$ & $9.40 \pm 13.04$ & $11.03 \pm 14.72$ & $2.806 * *$ & $\begin{array}{l}0.009 \\
(\mathrm{~S})\end{array}$ \\
\hline & Range & $4-48$ & $0-48$ & $0-48$ & & \\
\hline
\end{tabular}

Table 2. Disease activity indices

\begin{tabular}{cccccc}
\hline & Variable & Mean \pm SD & Range & $\begin{array}{c}\text { Paired T } \\
\text { test }\end{array}$ & P value \\
\hline $\begin{array}{c}\text { Swollen } \\
\text { joints }\end{array}$ & Aft start & $7.17 \pm 2.60$ & $1-12$ & & \\
& After 6 months & $5.57 \pm 2.90$ & $1-12$ & 4.218 & $<0.001(\mathrm{HS})$ \\
Tender & At start & $5.23 \pm 3.23$ & $0-12$ & 3.471 & $0.002(\mathrm{~S})$ \\
joints & After 6 months & $7.80 \pm 4.60$ & $3-20$ & & 0.004 \\
& After 12 months & $7.53 \pm 4.21$ & $2-18$ & 3.179 & $(\mathrm{~S})$ \\
VAS & At start & $58 \pm 18.64$ & $30-90$ & 3.515 & $<0.001(\mathrm{HS})$ \\
& After 6 months & $40.67 \pm 20.16$ & $10-90$ & 5.277 & $<0.001(\mathrm{HS})$ \\
& After 12 months & $39.67 \pm 22.51$ & $10-90$ & 4.097 & $<0.001(\mathrm{HS})$ \\
DAS & At start & $5.88 \pm 1.01$ & $3.85-7.66$ & & \\
& After 6 months & $4.89 \pm 1.13$ & $2.78-7.08$ & 7.329 & $<0.001(\mathrm{HS})$ \\
& After 12 months & $4.99 \pm 1.28$ & $2.75-6.81$ & 4.194 & $<0.001(\mathrm{HS})$ \\
\hline
\end{tabular}




\section{Discussion}

Mean of age of our study group was 43 years, with SD 10.5, and ranged from 24 to 60 years, the study group included 28 females (93.3\%) and only 2 males $(6.7 \%)$, duration of symptoms was 7 years, with SD 4.3, and ranged from 2 to 20 years, in comparison to study of Garrigues et al. (6) which composed of 29 women (72\%) and 11 men $(28 \%)$, mean age in their study was 55.9 years (SD: 14) and mean disease duration was 11.2 years (SD: 8.7).

26 patients $(87.6 \%)$ in our study complained of morning stiffness at start of follow up but number of patients who complaining decreased to 13 patients $(43.3 \%)$ after 6 months, they became only 9 patients $(30 \%)$ after 12 months, and this difference was significant $(\mathrm{p}$ value $=0.04)$. Only 2 patients in our study group had extraarticular maniestations at start of follow up and still after 6 months with significant difference ( $\mathrm{p}$ value $=$ 0.002). As regards treatment there was non significant difference between different times of follow up regard steroids and DMARDS, but there was significant difference regard NSAIDS, monotherapy, and combination therapy.

When we done laboratory investigations to our patients, we found that there was significant difference between different times of follow up regarding APR as mean of both ESR and CRP decreased significantly from start up to 12 months, also there was significant difference regarding $\mathrm{RF}$ as $80 \%$ of patients had positive RF at start and this percentage increased significantly to $86.6 \%$ after 6 months, $96.7 \%$ after 12 months. On the other hand, there was non significant difference regard $\mathrm{CBC}$ parematers (WBCs, PLTs, and HB).

Clinically, we found that there was high significant difference between different times of follow up (start, 6, 12 months) as regards count of swollen joints, tender joints, VAS, and DAS ( $p$ value $<0.001)$ as mean value of them decreased significantly from start up to 12 months. This was in agreement with results of Terslev et al. (7) as they showed good correlation between clinical improvement of the joint and decrease in DAS 28 in a longitudinal study.

US is well known to be more sensitive and accurate than clinical examination and conventional radiography and would be better to detect and score erosions and inflammatory changes in the MCP joints of patients with RA ${ }^{(8)}$. By US, we found that there was high significant difference between different times of follow up (start, 6, 12 months) as regards RT US gray scale count, LT US gray scale count, Total US gray scale count, Total US gray scale number, Total US PD score count, and Total US PD joint number ( $p$ value $<0.001$ ) as mean value of them decreased significantly from start up to 12 months. By comparison between Right and Left hand regarding gray scale count and US PD score joint count, we found that mean Rt gray scale count and Rt US PD score joint count were higher than Lt gray scale count and Lt US PD score joint count at different times (start, 6, 12 months), and this difference was significant except for US PD score joint count at start, it was non-significant.

Consequently, these tools are of interest for monitoring RA patients in remission, we found that the baseline gray scale number and PD-US number can used as predictive tool for number of swollen and tender joints after 12 months by using linear regression analysis as follows:

Swollen joint $=0.722+($ US PD joint number at start $\mathrm{x} 0.304$ )

OR 
$=2.551+(\mathrm{US}$ gray scale number at start $\mathrm{x} 0.163$ )

Tender joint $=0.660+(\mathrm{US} P D$ joint number $\mathrm{x} 0.463$ )

OR

$=0.853+(\mathrm{US}$ gray scale number at start x 0.039)

This was in contrast with Dougados et al. ${ }^{(8)}$ as they also reported that for RA patients who were in disease remission or with low level activity, baseline gray scale number and PD-US number predicted relapse. Also several studies reported that the Doppler US subclinical synovitis presence is considered predictive for radiographic progression in the future ${ }^{(9)}$. In agreement with our results Peluso et al. (10) studied 96 patients with early and long-standing RA in stable clinical remission for at least 6 months (DAS < 1.6). US evaluation was on the second and third MCP, proximal interphalangeal joints and the wrist of two hands. Of the negative PD (PD-) RA patients, $20 \%$ had a clinical flare during the 12-month follow-up period compared with $47 \%$ of positive PD $(\mathrm{PD}+)$ patients $(\mathrm{P}=0.009)$, Scirè et al. (9) showed in $106 \mathrm{RA}$ with clinical remission that a PD signal was predicted of a future flare. In another one, the authors studied 93 patients with RA in clinical remission for 6 months, $26 \%$ of patients experienced a flare within the year, increased baseline PD activity was independently associated with risk of flare ${ }^{(11)}$.

\section{Conclusion}

We propose that the combination of grey scale US and PD could be used as a sensitive and reliable non-invasive and widely available method complementary to standard clinical assessment for evaluating rheumatoid synovial inflammation in daily management and clinical trials and can be used also, to predict the bad outcomes and destructive changes, control the activity of the disease as possible as we can to decrease the incidence of joint destruction and so, the deformity that will occur. The combination of grey scale US and PD could be used as a sensitive and more accurate method for early and subclinical detection of rheumatoid activity by early and subclinical detection of synovitis and hyper vascularization of affected joints which can not be detected by clinical assessment or by radiography. So, we have the ability to detect early activity to start more aggressive therapy to predict the destructive outcomes.

\section{References}

1. Aletaha D, Smolen J, Ward MM. Measuring function in rheumatoid arthritis: Identifying reversible and irreversible components. Arthritis and rheumatism. 2006;54(9):2784-92.

2. Pap T, Distler O. Linking angiogenesis to bone destruction in arthritis. Arthritis and rheumatism. 2005;52(5):1346-8.

3. Naredo E, Bonilla G, Gamero F, Uson J, Carmona L, Laffon A. Assessment of inflammatory activity in rheumatoid arthritis: a comparative study of clinical evaluation with grey scale and power Doppler ultrasonography. Annals of the rheumatic diseases. 2005;64(3):375-81.

4. Karim Z, Wakefield RJ, Quinn M, Conaghan PG, Brown AK, Veale DJ, et al. Validation and reproducibility of ultrasonography in the detection of synovitis in the knee: a comparison with arthroscopy and clinical examination. Arthritis and rheumatism. 2004;50(2):387-94.

5. D'Agostino MA, Said-Nahal R, Hacquard-Bouder C, Brasseur JL, Dougados M, Breban M. Assessment of peripheral enthesitis in the spondylarthropathies by ultrasonography combined with power Doppler: a cross-sectional study. Arthritis and rheumatism. 2003;48(2):523-33. 
6. Garrigues F, Jousse-Joulin S, Bouttier R, Nonent M, Bressollette L, Saraux A. Concordance between clinical and ultrasound findings in rheumatoid arthritis. Joint, bone, spine : revue du rhumatisme. 2013;80(6):597-603.

7. Terslev L, Torp-Pedersen S, Qvistgaard E, Bliddal H. Spectral Doppler and resistive index. A promising tool in ultrasonographic evaluation of inflammation in rheumatoid arthritis. Acta radiologica. 2003;44(6):645-52.

8. Dougados M, Jousse-Joulin S, Mistretta F, d'Agostino MA, Backhaus M, Bentin J, et al. Evaluation of several ultrasonography scoring systems for synovitis and comparison to clinical examination: results from a prospective multicentre study of rheumatoid arthritis. Annals of the rheumatic diseases. 2010;69(5):828-33.
9. Scire CA, Montecucco C, Codullo V, Epis O, Todoerti M, Caporali R. Ultrasonographic evaluation of joint involvement in early rheumatoid arthritis in clinical remission: power Doppler signal predicts short-term relapse. Rheumatology. 2009;48(9):1092-7.

10.Peluso G, Michelutti A, Bosello S, Gremese E, Tolusso B, Ferraccioli G. Clinical and ultrasonographic remission determines different chances of relapse in early and long standing rheumatoid arthritis. Annals of the rheumatic diseases. 2011;70(1):172-5.

11. Saleem B, Brown AK, Quinn M, Karim Z, Hensor EM, Conaghan P, et al. Can flare be predicted in DMARD treated RA patients in remission, and is it important? A cohort study. Annals of the rheumatic diseases. 2012;71(8):1316-21. 